\title{
CORRESPONDENCE
}

\section{ORIGIN OF CONVOLUTED LAMINAE}

SIR,-A serious flaw in J. E. Sanders's interpretation of the origin of convolute bedding (Geol. Mag., 1960, xcvii, 409-421) is implicit in the last few lines of his paper. He writes that " the phenomenon is known only from alleged turbidite sequences in the geologic record ", yet he recognizes that the velocity fluctuations which his interpretation requires are not believed to be associated with turbidity currents.

We can regard the normal unit of the turbidite sequence as having been deposited relatively quickly as a whole. In such a deposit it is most difficult to imagine convolute " folds" (which may be within, and some distance from, both top and bottom of such a unit) as being produced in the form of surface relief as "streaked-out ripples" by a fluctuating water current passing over a silty bottom deposit.

Of greater importance is that any theory of the origin of convolute bedding should positively take account of the association of the phenomenon with turbidite sequences. The mechanism suggested by Sanders could, and presumably would, operate equally in any other situation, provided that the bottom deposits were of the critical grade and that the appropriate fluctuating currents were present.

The particular feature of turbidite deposition that should be accounted for in any theory of the origin of convolute bedding has already been mentioned. It is that such deposits are laid down relatively quickly and as substantial units. Thus a comparatively large thickness of unconsolidated and water covered sediment is available at one time: perhaps for the operation of some process involving localized liquifaction and hence flow of the sediment. A promising explanation on these lines has recently been given by Emyr Williams in his paper on "Intra-Stratal Flow and Convolute Folding" (Geol. Mag., 1960, xcvii, 208-14), and more especially in an early draft of his subsequent letter on this subject (below) where he refers to the work of Terzaghi.

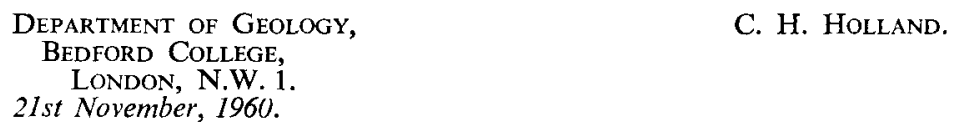

SiR,--It was with much interest that I read the stimulating new ideas put forward by Dr. J. E. Sanders to account for convoluted laminae (Geol. Mag., xcvii, 409-421). However, the mechanism proposed for the contortions is unacceptable for a number of reasons. It is stated that this mechanism is met only if the affected water-saturated and originally cohesionless sand can be alternately cohesive and cohesionless (p.419), but according to the experimental evidence known to the writer, such behaviour is unknown and does not appear probable. Again, it is pointed out that although convoluted laminae have been described only in alleged turbidites, the distortions according to this mechanism are anomalous when considering the theory of turbidity currents (p. 419) - which is based on much experimental work. Furthermore, convolute folding is typically characterized by very irregular attitudes of axial planes and directions of recumbency of the folds, which would be unlikely if the anticlines developed in a way similar to that of current ripples, as suggested by Sanders.

The occurrence in a number of examples of unconformities developed during the deformation causing convolutions is rightly stressed in Sanders' paper. In a recent paper (Geol. Mag., xcvii, 208-14) I was in error in not realizing their importance, for they must indicate, when they are present, that the deformation occurred not within beds confined between others, but within water-covered beds. 
Also of importance is that convolute folding is limited to sediment mainly of fine-grained sand and coarse silt, which is of the size-grade range susceptible to liquefaction. This fact coupled with the experimental observation that the structure of fine-sediment collapses quickly after deposition from turbidity currents (Dzulynski, Ksiazkiewiecz, and Kuenen, 1959, Bull. Geol. Soc. Amer., Ixx,1112), thus showing its initial metastable nature, indicates that it is necessary to reckon with the phenomenon of liquefaction.

Liquefaction is best understood by examining the shearing resistance equation of water-saturated unconsolidated sediment, and since, according to normal usage in soil mechanics, I misused the terms "effective" and " neutral" in the explanation given in my paper (p. 208) it is appropriate to reconsider this equation:-

$$
\mathrm{s}=\mathrm{c}-(\mathrm{p}-\mathrm{u}) \tan \phi
$$

where $\mathrm{s}=$ shearing strength; $\mathrm{c}=$ cohesion; $\mathrm{p}=\gamma_{\mathrm{s}} \mathrm{z}_{\mathrm{s}}$, wherein $\gamma_{\mathrm{s}}$ is submerged unit weight of sediment and $z_{8}$ depth below free surface of sediment; $\mathrm{u}$ is pore water pressure in excess of value of $\gamma_{\mathrm{w}} z_{\mathrm{w}}$, wherein $\gamma_{\mathrm{w}}$ is unit weight of water and $z_{w}$ depth below water surface; $\phi=$ angle of internal friction. Normally " $u$ " is zero. However, if a metastable structure in a granular, cohesionless $(c=0)$ sediment collapses, the term " $u$ " increases almost immediately from zero to a value which may be close to the pressure " $p$ ", with the result that the shearing strength of the metastable deposit drops to a value which may be close to zero, when the sediment temporarily behaves as a liquid (see Terzaghi, 1957, Teknisk Ukeblad Oslo, nr. 13-14, 1-3).

Terzaghi ( $\mathrm{ibid}$.) discusses examples of the liquefaction of fine-grained and cohesionless sediment in terms of impulses received from earthquakes, blasting operations, and seepage pressures exerted by the flow of ground water towards the ocean during very low tides, etc. Of particular interest are his conclusions regarding the liquefaction of water-covered sediment, which may be resting on flat surfaces. It is maintained that liquefaction commonly starts at a point and spreads over an increasingly larger area. However, because sedimentary deposits with an unstable texture usually contain layers and lenses of material with stable texture, liquefaction proceeds erratically, and there are relative displacements within the agitated sand. The mechanics of progressive liquefaction are explained by considering that some of the excess water expelled from the temporarily liquefied part percolates laterally causing liquefaction of the intact portion.

According to Terzaghi's mechanism for progressive liquefaction it seems that contortion of laminae must result from the displacements within affected water-covered, fine-grained, unstable, and cohesionless sands, even when they are reposing on flat surfaces. Due to the lateral percolation of some of the expelled water from liquefied parts, the development of the folds would closely follow the patterns given in my paper, and the deformation would die out against an approximately smooth bottom. It is suggested that the topmost material, as a result of agitation with the escape of part of the expelled water upwards, resettles giving a smooth surface, so that the folds within the affected layer would, in general, appear to die out against the upper margin, although slight unconformities would be expected.

In a private discussion during July-August, 1960, Dr. C. H. Holland implied that none of the causes listed in my paper for intra-stratal flow within confined layers satisfactorily explained the convolute folding occurring with random orientation within medium-coarse calcareous quartz siltstones, which are considered to be turbidites, in the Lower Ludlovian rocks of NorthEast Radnorshire (Holland, 1959, Geol. Mag., xcvi, 230-6). He wondered if the mechanism proposed could be applied to the sedimentary layer immediately after deposition. On my suggesting that in these rocks convolute folding may have resulted from the liquefaction of unconsolidated watercovered beds as described above, since some of the crests of the folds are cut off by succeeding laminae (p. 231), Holland stated his support.

It appears that liquefaction would occur in water-covered sediment with a much narrower size-grade range of material and a more unstable texture 
than in water-logged confined layers, from which water would not be immediately expelled during disturbance. It is also considered likely that the directions of the convolute fold axes, which according to my mechanism depend to a large degree on the distribution of the pockets of material that had retained a notable shearing strength, would be more haphazard resulting from the liquefaction of water-covered deposits than in examples due to directed movements within confined layers.

Finally, it may be noted from the foregoing that the reasons which make Sanders' mechanism unacceptable are satisfied by the mechanism proposed by the writer. In addition, exaggeration, distortion, and overturning of primary upward protuberances, and the inversion of the filling of depositional depressions, as well as the irregular attitudes of the axial planes and directions of recumbency of the folds, can be adequately explained by laminar flow within liquefied layers, whether confined or, in the examples where unconformities developed during deformation, water-covered.

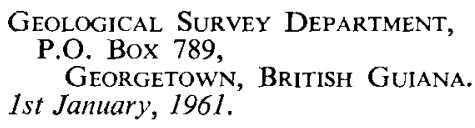

(Published by permission of the Director of the Geological Survey of British Guiana.)

\section{THE PATTERN OF SOME PACIFIC ISLAND CHAINS}

SIR, - The article entitled, " The Pattern of Some Pacific Island Chains," by L. J. Chubb (1957) has just reached the present author. Chubb's main hypothesis deals with the evolution of the island chains and origin of the coral reefs as follows: "Nearly all the islands discussed in this paper must have originated in pre-glacial times, so they would be expected to furnish evidence of any post-glacial rise in sea-level. But this rise would have been everywhere equal, the sea cannot have risen by different amounts around different islands, yet the degree of drowning of the coasts and the stage in the development of reefs varies from island to island within any one chain. The only explanation of this fact is that each island subsided independently, . . " (italics supplied).

The writer, during nearly two decades as District Geologist in the Hawaiian Islands and as Geologist-in-Charge of Pacific Ocean investigations for the Geological Survey, has never found any fact to substantiate Mr. Chubb's conclusion. For example, on page 222 he states, "The Hawaiian chain shows a very complete sequence but it is characterized by the absence of drowned river-yalleys and of barrier reefs, though fringing-reefs and atolls occur" (italics supplied). All of the islands where not veneered with recent lava have deeply drowned river valleys which have been described in the literature since 1935 (Stearns 1935a, 1935b, 1935c, 1946a, and Stearns and Vaksvik 1935). Logs of wells at the mouths of these valleys indicate that the subsidence amounts to more than 1,200 feet.

In the same paragraph on page 222 Chubb states: " Eastward lies Kauai, an ancient volcano so deeply dissected that all trace of its original form is lost." Kauai contains near its centre a lava filled caldera 10 miles across and although it is deeply eroded there is no difficulty in tracing its original form (Stearns 1946a, Macdonald, Davis, and Cox 1960).

On page 223 Chubb states: "The only important embayment within the chain, Pearl Harbour in Oahu, is due, not to the drowning of a river-valley, but to the depression between the two volcanoes composing the island being still below the sea. This need have involved neither subsidence of the island nor a rise of sea-level." Pearl Harbour is due to the drowning of rivervalleys (Stearns 1935a and b, and Stearns and Vaksvik 1935). The contact of the Koolau and Waianae lavas lies several miles west of Pearl Harbour.

On the same page he states that Tau, Olosenga, Ofu and Tutuila Islands in 